\title{
LAS ETNICIDADES DESDE EL YO-JOVEN, SUS CONFIGURACIONES EN LA FRONTERA NORTE MEXICANA
}

\author{
ETHNICITES OF SELF-YOUTH, THE CONFORMATIONS IN THE NORTHERN \\ BORDER OF MEXICO
}

\author{
ETNICIDADES DO EU-JOVEM, CONFIGURAÇÕES NO FRONTEIRA \\ NORTE MEXICANA
}

Olga Lorenia Urbalejo Castorena

Doutora

Instituto de Investigaciones Históricas

lurbalejo@uabc.edu.mx

Mexico

\section{Resumen}

El análisis de este texto se dirige a los y las jóvenes que, mediante su experiencia de vida en un contexto excluyente, redefinen la etnicidad; manteniéndose, en ocasiones, distantes de la dinámica social que lleva como objetivo principal centralizar lo indígena como formación identitaria. En la investigación, realizada desde la etnografía, se muestran las generalidades institucionales de lo joven en el marco urbano y el entorno social de la población indígena, así como la relación que existe entre dichos habitantes y los/las jóvenes de primera o segunda generación. También se presenta un análisis de la configuración de la etnicidad de los jóvenes, basada en la experiencia individual de un yo que se muestra en dicho contexto. Finalmente se exponen algunas actividades que se realizan ligadas con la esfera política étnica y con el trato actual que se presta a los niños y niñas, quienes se convertirán en jóvenes indígenas y marcarán un nuevo cambio generacional dirigido a un yo-grupal.

Palabras clave: Etnicidades, jóvenes, participación política, escenario social.

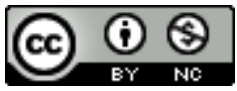




\begin{abstract}
The analysis of this text is aimed at young people who, through their experience of life in an exclusionary context, redefine ethnicity; maintaining, at times, distant from the social dynamic that has as main objective to centralize the indigenous as identity formation. This ethnographic research shows the institutional generalities of the young in the urban setting and the social environment of the indigenous population, as well as the relationship that exists between these inhabitants and the first or second generation young people. It also presents an analysis of the ethnicity configuration of young people, based on individual experience, of a self that is shown in that context. Finally, some activities are presented, linked to the ethnic political sphere and the current treatment given to children, who will become indigenous youth and mark a new generational change directed to a group ego.
\end{abstract}

Keywords: Ethnicities, youth, political participation, social scene.

\title{
Resumo
}

A análise deste texto é dirigida a jovens que, através de sua experiência de vida em um contexto excludente, redefinir a etnia; permanecendo, às vezes, distante do dinâmica social cujo objetivo principal é centralizar o indígena como um formação identitária. Na pesquisa, realizada a partir da etnografia, as generalidades são mostradas dos jovens no cenário urbano e no meio social da população indígena, bem como a relação que existe entre esses habitantes e a primeira classe segunda geração Uma análise da configuração étnica de jovens, baseados na experiência individual, de um eu que é mostrado naquele contexto. Finalmente, algumas atividades que são realizadas, ligadas à esfera política, estão expostas etnia e com o tratamento atual dado às crianças, que se tornarão uma nova mudança geracional voltada para um eu no grupo.

Palavras-chave: Etnicidade, jovem, participação política, paisaje social. 
a situación de la población indígena denominada como migrante, en algunas ciudades de la frontera norte de México, como en el caso de Tijuana, se ha visto acompañada de una gestión de más tres décadas, que los ha llevado a conformar asociaciones civiles que resultan ser el mecanismo de comunicación y mediación con los gobiernos municipales. Esta particularidad se desprende de la reconfiguración de las formas organizativas del lugar de origen al de recepción (en los procesos migratorios). En el abordaje desde las organizaciones, encontramos que los indígenas en la ciudad, buscan el reconocimiento social e institucional- o institucionalizado- y una participación en la política que desde las administraciones públicas se realiza; dicha labor ha construido una parte del paisaje de lo étnico-urbano en la frontera. Así, la vida pública de los grupos indígenas ha estado dirigida, mayoritariamente, por hombres adultos y ancianos, mientras que en una generalidad las y los jóvenes se ausentan de las dinámicas que ponen al centro de las identificaciones a lo indígena, no obstante, encontramos que hay un grupo que comparado con quienes no se visibilizan desde una adscripción étnica puede resultar pequeño numéricamente, pero participan en una definición de lo étnico desde su juventud y no lo hacen accediendo a las organizaciones mencionadas, sino mediante una variedad de actividades como la música, la danza, la gestión cultural y la política.

El análisis de este texto se dirige hacia las y los jóvenes, quienes, desde una experiencia de vida en un contexto de exclusiones, están redefiniendo las etnicidades en centros urbanos como Tijuana, al cuestionar -a través de su participación- quiénes y cómo son los indígenas en la ciudad, lo cual hacen desde un reconocimiento personal desde su distinción como jóvenes indígenas, y no anteponiendo a la grupalidad, como se hacía regularmente, lo anterior es un cambio generacional que se marca como coyuntural. Es importante mencionar que no se tiene ninguna pretensión determinista respecto a que el ser indígena se identifica solamente cuando se está mediado por el Estado, sino que dadas las particularidades locales las dinámicas de la juventud étnica se enmarcan en esta relación institucional.

La metodología con la cual se han recabado los datos empíricos presentados en este artículo, es de corte cualitativo, por lo cual se utilizaron las herramientas de la etnografía, realizando observación en espacios donde se incluyen las viviendas, escuelas, las colonias que concentran población indígena, lugares de trabajo, centros de reuniones como canchas 
deportivas y centros comunitarios, e instituciones públicas relacionadas con la difusión cultural, donde eventualmente hay participación de los indígenas. Se realizaron entrevistas abiertas, tanto a jóvenes como a mujeres y hombres adultos y entrevistas semi estructuradas a funcionarios municipales vinculados la normativa del tema de juventud en Tijuana. Lo anterior se realizó durante el desarrollo de investigaciones académicas que han llevado en el centro de la discusión el eje analítico de lo étnico, siendo 2018 cuando se hizo el último acercamiento a campo.

En el artículo se desarrollan tres apartados, el objetivo del primero es mostrar algunas generalidades del panorama institucional de lo joven en la ciudad, así como plantear el entorno social de los habitantes indígenas y la relación que se entabla con los y las jóvenes; el punto de partida son estas circunstancias, para luego proseguir con la presentación y el análisis de cómo se configura la etnicidad desde la experiencia individual de un yo que se sitúa en ese escenario, tema que se desarrolla en el segundo apartado. En el tercero se presentan algunas de las actividades que en relación con la esfera política étnica se realizan y concluyo con el cuidado actual que se procura para niños y niñas, futuros jóvenes indígenas.
No obstante, lo que se presenta enseguida se refiere a una geografía particular, se considera que lo expuesto posibilita un diálogo con juventudes en diferentes latitudes, al tener en cuenta el contexto amplio y los vínculos históricos de permanencias excluyentes hacia quienes tienen adscripciones étnicas. Habrá que comprender en esos términos a las y los jóvenes indígenas a quienes se les continúan viendo como inferiores desde una jerarquía socioraciacializada, y es en ese escenario que resulta complejo el tener una presencia y expresividad política fuera de la norma y espacios ya establecidos.

\section{Apuntes contextuales de las relaciones de los y las jóvenes en Tijuana}

La frontera norte mexicana se formalizó como tal, es decir como frontera, desde la firma del tratado de Guadalupe Hidalgo en 1848, cuando se establecieron los límites territoriales con Estados Unidos. Se distingue por ser ícono de una economía industrial, y reconocida como polo de atracción para migrantes, así también por sus relaciones binacionales con el país vecino. Dentro de la zona fronteriza destaca la ciudad de Tijuana, Baja California, ubicada en el noroeste de México, en colindancia con el estado 
norteamericano de California, con el cual ha tenido una relación permanente, estrecha y asimétrica.

La historia de la ciudad comprende hitos como el auge turístico ligado al haber sido un centro de cantinas, casinos $\mathrm{y}$ prostitución en la década de 1920, demandado por los visitantes de California; y al desarrollo y posterior consolidación de una industria económica sustentada en el sector maquilador, lo anterior desde la implementación del Programa de Industrialización de la Frontera en 1965. La conjunción de sus características han permeado la vida de sus habitantes, y de entre estos, tan diversos como la misma frontera, se destacan a los que llegaron hasta las coordenadas del norte en busca de empleo, y a quienes dentro de sus identificaciones se encuentra el pertenecer a un grupo étnico, que en una experiencia de vida compartida en el aspecto laboral, se colocaron del trabajo en el campo al de la maquila (de ensamblaje y manufactura principalmente) y en el de servicios, pasaron de ser propietarios de tierras en espacios empobrecidos a un trabajo asalariado y precarizado.

Tijuana se había mantenido desde que se fundó en 1889, como un espacio fronterizo mestizo, aun teniendo entre sus primeros pobladores a indígenas de la etnia kumia, una de las originarias del norte de la península de Baja California (Piñera, Ortiz y Lugo, 1985: 19). Así, como ha sucedido en otras ciudades con migraciones indígenas, las políticas para esa población se suscitan una vez que hay un crecimiento demográfico, como lo señala Urteaga, (2014:162), es por eso que dicha población se ve involucrada en la elaboración de las políticas. De tal manera que como habitantes de Tijuana, algunos y algunas se han destacado por dirigir a sus grupos, observando en las gestiones de los líderes y las lideresas un interés por relacionarse con sus cosmovisiones y vida en la ciudad, lo que se realiza mediante la conformación de asociaciones civiles, mesas directivas y cofradías religiosas. La participación desde estas acciones han sido un medio de vinculación con las dependencias de gobierno (locales, estatales $y$ federales) funcionarias $y$ funcionarios, Organizaciones No Gubernamentales (ONG's) y otras asociaciones civiles; se podría decir que la menor vinculación o lazos son lo que se hacen con la población en general, entre quienes persiste una visión racista $\mathrm{y}$ clasista hacia los y las indígenas.

Se ha ubicado a las mujeres indígenas como trabajadoras en el comercio ambulante, espacializadas de manera principal en las inmediaciones de la garita internacional entre Tijuana y San 
Ysidro (condado de San Diego, California). A este trabajo "despreciado" además se le ha atribuido la responsabilidad de ensuciar la ciudad, de ahí que la insistencia de una "sanidad social" en el área ${ }^{1}$ resulte una demanda recurrente. Lo anterior bajo el discurso moral de la negación de una Tijuana empobrecida e india, a lo que se adjunta un reclamo social del cuidado materno; debido a que es una constante la inclusión de niños y niñas en el trabajo de sus madres, ya sea para vender o pedir dinero ${ }^{2}$. Considero pertinente señalar que este discurso queda inserto en otro más amplio que conjunta exclusión por raza y condición migrante, es aquél que se refiere al nativismo y que también define a otras ciudades con una amplia población migrante. Para el caso, la antropóloga Areli Veloz menciona que luego del crecimiento poblacional de Tijuana entre 1970 y 1990 se

\footnotetext{
${ }^{1}$ Los cambios en la estructura de la zona de la garita han llevado a un desplazamiento de los y las comerciantes que ahí se ubican, lo que incluye a quienes ejercen el ambulantaje legal e ilegalmente, sin contar con los permisos requeridos.

${ }^{2}$ Distintas campañas se han realizado para que los niños y niñas no trabajen en las calles o no sean acompañantes de sus madres, una de estas durante la administración municipal de Jorge Hank Rhon (2004-2007) y bajo la cual a los hijos e hijas de madres indígenas, trabajadoras informales del comercio ambulante, se les ofreció como estímulo económico una beca escolar mensual de 500 pesos; además de la apertura de un taller de costura en la colonia Valle Verde, ubicada al este de Tijuana, para el autoempleo de las mujeres (Urbalejo, 2011).
}

Generó malestar entre la población previamente establecida o aquella que se asumía como protectora de la buena imagen de la ciudad. Este malestar se evidenció en la exacerbación de un nativismo esencialista en y por (cursivas de la autora)la ciudad, que asoció la migración con la mala imagen de Tijuana y, por ende, se interpretó como una barrera para la estabilidad económica de una ciudad en crisis y para los proyectos sociales y económicos perfilados a su progreso. Además, este nativismo compaginaba y era exaltado por los postulados políticos de los grupos políticos conservadores en la ciudad [...] (Veloz, 94-95, 2017).

En un escenario con una participación adultocentrista y atención incipiente a la niñez, a lo que se agregan escuelas de educación intercultural bilingüe, a nivel primaria y secundaria, es que los y las jóvenes aparecen muy poco, al menos desde su adscripción étnica. Plantear un panorama donde hay poca representatividad podría parecer contradictorio, pero es precisamente la intención al hacerlo; para desarrollar el análisis de la etnicidad propiciada desde lo individual, así como observar su presencia e intervención en un espacio como el señalado.

Es pertinente mencionar que no hay una sola forma de ser joven indígena y los estudios sobre juventud étnica han permitido conocer la base de esa diversidad, Jahel López (estudiosa de las 
mujeres jóvenes indígenas) señala que en México finalizando la década de 1980 y durante la de 1990 fue cuando los jóvenes indígenas se consideraron para las investigaciones académicas y se abordaron como sujetos de cambios, desde las relaciones intergeneracionales y de género, y posteriormente hubo un planteamiento acerca de las identidades étnicas en un contexto vertiginoso de cambios que luego incluiría la intensa migración (nacional e internacional) de este grupo sociocultural (López, 2018: 25). Dos de los estudios pioneros sobre la juventud étnica son los de Martiza Urtega del Pozo, "Lo juvenil en lo étnico. Migración juvenil indígena en la sociedad contemporánea mexicana"(2008) y el libro coordinado por Maya Lorena Pérez, Jóvenes indígenas y globalización en América Latina (2008), acerca de la autora también encontramos sus posteriores investigaciones focalizadas en jóvenes mayas de la península de Yucatán, México. Ambas antropólogas son precedentes para la multiplicidad de estudios sobre jóvenes indígenas con los que contamos hoy, los cuales se han realizado en espacios rurales y urbanos, y entre dichos trabajos se encuentra los realizados como tesis de licenciatura y posgrado en las distintas instituciones académicas.
Urtega señala que la, "juventud es una variable de análisis social y no puede ser separada de otras variables, como género, clase, etnia, región, entre otras" (Urteaga, 2017). Atendiendo a lo anterior, la consideración de ubicar a los jóvenes indígenas en sus dimensiones espaciotemporales y socio-históricas permite conocer las particularidades de las juventudes étnicas, aun habiendo un eje que enlaza la experiencia de los y las jóvenes, se trata de la condición de raza, lo que genera desigualdad y exclusiones en los espacios urbanos. Es precisamente en los entornos de ciudad donde se privilegia un modo de juventud configurada desde el capitalismo que la liga a la educación, y las políticas de juventud son dirigidas precisamente a jóvenes estudiantes (Balardini, 2000: 14).

En un imaginario conformado sobre la juventud urbana lo étnico no tiene cabida, en primer lugar porque la juventud es una etapa de vida que se incluye como tal entre los diversos grupos indígenas mediante varios factores, uno de ellos el educativo que tiene su antecedente en el Proyecto Tarasco, puesto en marcha durante la gestión como presidente de la República Mexicana de Lázaro Cárdenas del Río (1934-1940). Se trató de un programa de educación bilingüe, planteado para alfabetizar y escolarizar a los 
hablantes de la lengua tarasca (purépecha) en la zona rural de la cañada de los 11 pueblos en el estado mexicano de Michoacán; el proyecto fue parte de una serie de acciones del presidente Cárdenas para integrar a los indígenas a un proyecto de nación. De tal forma que, la conformación de una juventud indígena quedó mediada por lo educativo, pero exenta de lo urbano, que como ya se mencionó, se incorpora a este escenario de ciudad en el auge de las migraciones.

Tijuana claramente no queda fuera de los procesos nacionales y el imaginario de la juventud estandarizada y en relación a una normativa que deviene de las instituciones, lo étnico ha quedado excluido $^{3}$. Por otro lado, las y los jóvenes tienen muy poca relación con la vida pública de sus grupos, ya sea por decisión propia y/o porque es parte de la dinámica al interior, al no ser considerados para decisiones y la vida pública. Con el mismo propósito se expone la inexistente relación -mediante la identificación étnica- con las instancias encargadas de la juventud en Tijuana, siendo la más importante el Instituto Municipal de la Juventud.

Sin una precisión en números sobre la cantidad de jóvenes que viven en Tijuana, lo anterior desde los parámetros

32017 es el último año en que COPLADE actualizo el dato. marcados por edad, parto de los datos proporcionados por el Comité de Planeación para el Desarrollo del Estado (COPLADE), quien expone que para $2017^{4}$ la población joven de los 15 a los 29 años de edad es de, 228,025 hombres y 224,591 mujeres, considerando que la población total de Tijuana, es de de 1 millón 773 mil 558 habitantes, los hombres jóvenes representan el $13.6 \%$, de la población total, mientras que las mujeres el $13.21 \%$. Los números se presentan así, con la intención de tener un panorama del universo donde quedan insertos los jóvenes indígenas, sobre quienes no hay datos cuantificados. El número también resulta de interés porque refiere a una cantidad que técnicamente debería estar vinculada al Instituto Municipal de la Juventud (20162019), el cual en una somera descripción de sus funciones refiere ser un "Instituto que desarrolla programas de impacto, brindando oportunidades y herramientas para el desarrollo integral de los jóvenes, coadyuvando al vínculo de organismos públicos, privados $\mathrm{y}$ sociales $[\ldots]$ " (IMJUV, 2019). Quisiera dejar clara la idea de que el objetivo no es indicar que es únicamente por la intersección étnica que los y las jóvenes deben ser abordados por las instituciones del Estado, sino continuar

\footnotetext{
${ }^{4}$ Para un estudio que profundice sobre el tema se puede consultar, Imaginarios juveniles: Un análisis desde la condición étnica y urbana de los jóvenes mixtecos en Tijuana (Urbalejo, 2014).
} 
con la problematización de su escenario social.

Retomando el tema del IMJUV, habría que decir que en la actual administración municipal (2016-2019) parece haber un tema prioritario (por lo menos a nivel mediático) que es el del Programa de Transporte Gratuito para Estudiantes (RAITE), donde al ser estudiante de nivel medio y superior, con una edad de 12 a 29 años y con previa inscripción, se puede acceder a transporte público gratuito (dos veces por día y de lunes a viernes). RAITE configura así a los y las jóvenes a estar inscritos en una normatividad de educación, lo que vincula a la presente administración con las anteriores, al ser el sector escolarizado uno de los más beneficiados. Es secuencial también el desconocimiento de una población indígena y joven.

En entrevistas hechas a dos ex directores y una ex directora de este instituto, la constante ha sido no tener una vinculación con el tema indígena, a lo que de igual manera se atribuye que la población está concentrada en la zona este $^{5}$, lo que traigo al diálogo por una de

\footnotetext{
${ }^{5}$ La zona este de Tijuana colinda con el municipio de Tecate, en Baja California, Campos y Hernández ubican el crecimiento y fraccionamiento en colonias de esta zona en la década de 1980 (Campos y Hernández, 2015: 151)- Se ubican en este espacio algunas de las colonias con alta concentración de población de cinco años y más que habla una lengua indígena
}

las respuestas dados por Jorge Mario Madrigal Silva ${ }^{6}$, Director Municipal para la Juventud en Tijuana (2013-2016), al preguntarle si atendían a jóvenes indígenas:

La verdad es que no, nos tocó el año pasado apoyar a un grupo $[\ldots]$ cuando quisimos (el IMJUV) apoyarlos fueron muy inconstantes en la manera de atender al joven, el área (SIC) si era muy difícil, pero también en el tema de territorio en el cual nos pidieron que era por cerca del Maclovio (la colonia Maclovio Rojas está en la zona este) desconozco, si era muy difícil de poder entrar, entonces nada más un apoyo de mochilas para los jóvenes que se les dio el año pasado pero en lo personal es una mala experiencia porque eran bastantes requisitos en los cuales no los cubre [...] también tenemos que reconocer que no venimos con esa cultura para atenderlos, $[\ldots] \mathrm{y}$ no nos hemos metido para nada.

Estudiantes a nivel secundaria $\mathrm{y}$ preparatoria han logrado que se les canalice para obtener becas negociadas por los líderes de organizaciones indígenas. Durante el gobierno municipal de Hank Rhon (2004-2007) la asociación civil Mixtecos de Valle Verde logró que se instalara un pequeño centro de cómputo en su salón comunitario, éste era administrado

(Velasco, 2008). Actualmente se distingue además por ser una las zonas más violentas de Tijuana

6 El funcionario renunció a su puesto luego de cumplir con dos de los tres años de la gestión que le correspondía, para buscar otro puesto político. 
por el Instituto de la Juventud, pero funcionó poco tiempo.

Desde una perspectiva de exclusión por quienes no están vinculados a los grupos indígenas -la población y las instituciones- y la poca inserción en la dinámica de las organizaciones, a lo que se añade una "desadscripción” desde lo étnico por parte de los y las jóvenes, el panorama de la participación de una juventud indígena se podría avizorar decadente, por llamarlo de alguna forma. Aún con estas atenuantes hay jóvenes que lo hacen, enseguida se presentan algunos de los casos. Retomo dos concretamente para dar una comprensión del proceso.

\section{Configuración del yo étnico}

En una vertiente de los estudios sobre jóvenes se encuentra una discusión sobre la etnicidad y juventud, donde pareciera son excluyentes una categoría de la otra. Para abordar el tema retomo lo aportado por Kropff y Stella (2017), que en sus conclusiones apuntan:

Si la discusión de los estudios étnicos permitió que la antropología dejara de tener por objeto a los indígenas y "su" diferencia para colocar en el foco del análisis la coproducción de etnicidades y nación, este enfoque construye como objeto al proceso mismo de construcción y disputa de alteridades etarias. [...] las construcciones etarias, al igual que las étnicas, son objeto de disputas que generan una arena en la que emergen subjetividades que cargan con interpelaciones diversas.

Se incorpora a estas subjetividades la contraposición entre lo rural y lo urbano, separación que se observa como perene al ser referidos como espacios socioculturales donde surgen y se configuran los modos de vida, y donde lo rural mantiene una denotación de atraso y por ende se tuviera que decidir entre pertenecer a uno u a otro, lo que sería logrado a través de la práctica, pero sabemos que lo étnico está en la ciudad, en esas "interpelaciones diversas" que mencionan las autoras, aun así hay una continuidad al interiorizar dicha percepción, que al ser o estar en la ciudad no se es indígena, evidencia de ello se observa en las siguientes frases recuperadas de una entrevista que realicé en 2018 a Maribel Velasco (sobre la cual abundaré posteriormente). Maribel expone la reflexión de niños y niñas con los que convive en Tijuana: "nací en Oaxaca pero yo no soy indígena porque vivo en Tijuana”, “yo nací en Tijuana, si yo nací en Tijuana yo ya no soy de una comunidad indígena".

Los y las jóvenes referidas en este texto se socializaron con las consideraciones expresadas, y en un 
espacio social étnico-urbano, considerando que el espacio social se compone por "lo político-institucional y con lo cultural ideológico" (Santos, 2009: 147) y es ahí el lugar donde se dan los procesos de etnicidad que referimos.

Dado lo expuesto, estaríamos pensando que los y las jóvenes no se siente identificados con las prácticas que conllevan a ser vistos como indígenas, pero conviven entre relaciones familiares y grupales que tienen perspectivas claras y objetivizadas del cuidado de su cultura $\mathrm{y}$ observan también las estrategias donde se intenta involucrarlos, por ejemplo, el incluirlos en las bandas de música y danza. A Eleuterio nacido en Ixpantepec Nieves, en la mixteca oaxaqueña (que siendo niño llegó a vivir a Tijuana), podríamos definirlo actualmente como un comprometido líder indígena. En su experiencia de vida está el haber aprendido mediante su mamá y papá, las costumbres y las tradiciones de Oaxaca. No así sus hijos, quiénes nacieron en Estados Unidos y crecieron entre ese país y México, por lo que no se consideraban como mixtecos. Eleuterio los ha involucrado con una banda de música tradicional (el género musical es chilena) fundada por adultos y donde ya participan niños y jóvenes, así lo narra:
[...] y se me ocurre meter a mis hijos, y ellos como que no querían porque escuchan músicas en inglés y esos rollos, pero les digo, "no, sí es importante que aprendan esto" casi llorando los metí. Entonces ya invité a uno, y ya se clavó (entusiasmó), y ahí le fui metiendo el gusanito y ya de repente lo veo con la banda ya grande y empezaron a meterlo más, entonces ya invitamos al otro niño que es Héctor, un niño chiquito, y le empezó a pegar, y ahí meto a mi hijo, Alejandro, y empieza a pegar (a utilizar instrumentos de percusión).

Este ejemplo es representativo de cómo mediante proyectos de los adultos los jóvenes se incorporan a ciertas actividades, sin que eso quiera decir que tome para ellos y ellas el mismo sentido. Como lo podemos ver con Sergio (entrevistado en 2016 cuando tenía 26 años), nacido en Tijuana con papá y mamá de la mixteca de Oaxaca; asistió a una Primaria del sistema de educación intercultural bilingüe $y$ después a la Secundaria y Preparatoria del sistema educativo regular, sabiéndose de una familia migrante e indígena no se definía como tal, dice no haberse sentido discriminado en su entorno, aunque sí conocer de otras personas que eran llamados con palabras que pueden resultar un insulto, como oaxaco ${ }^{7}$ y escuchar que imitaban voces para hacer referencia a cómo hablan los indígenas. La primera vez

\footnotetext{
${ }^{7}$ El gentilicio de Oaxaca es oaxaqueño y oaxaco se
} utiliza de una forma denostativa 
que Sergio asistió a un evento "indígena" fue en 2012, al recibir la invitación de su tío para participar en la fiesta patronal de San Esteban (santo del pueblo San Esteban Atatlahuaca, de la mixteca de Oaxaca). La asistencia -que no participación- de jóvenes a estas celebraciones no es extraña, porque hay música, bailes y torneos de básquetbol que les son atractivos. En cambio Sergio dice haberse involucrado más, "y la verdad si nos daba vergüenza bailar al principio, nos daba pena pues, tenía la pena de bailar la danza y todo eso, o participar, pero ya con el tiempo se nos hizo normal y pues ya lo aceptamos pues que somos de...(indígenas)". En la siguiente fotografía observamos a un conjunto de jóvenes en la celebración patronal, pero manteniéndose a distancia, escenas reiteradas en las celebraciones a los santos.

IMAGEN 1 Jóvenes espectadores de la fiesta patronal de San Esteban, colonia el Pípila, Tijuana, 2017. Olga Lorenia Urbalejo.

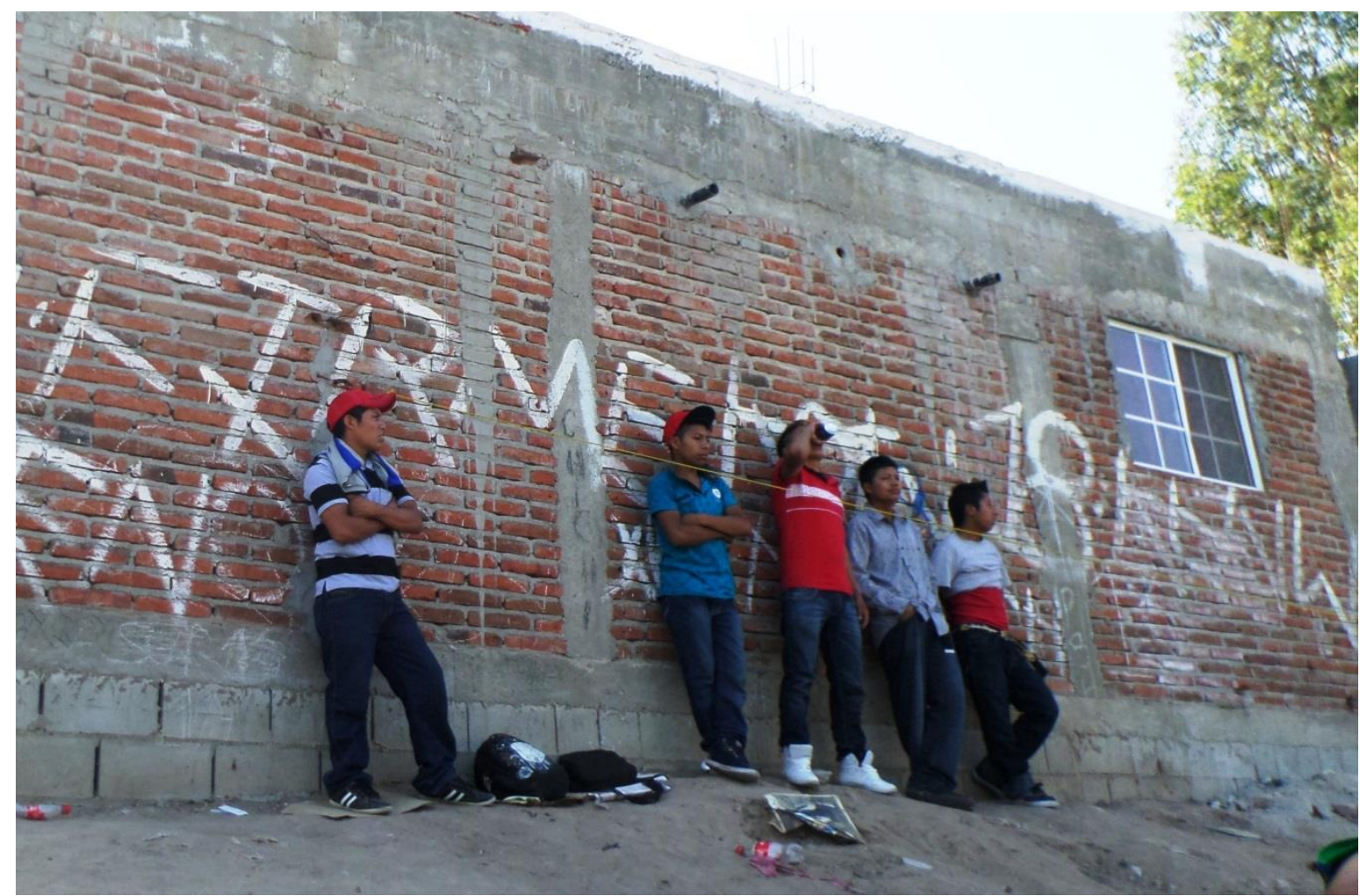

Las actividades de Sergio de Romeo Pérez, de Putla, Oaxaca; Sergio continuaron y junto a otros jóvenes se les trasmitió la enseñanza de la danza, por parte buscó financiamiento para los trajes de su grupo de danza. El haberse involucrado lo 
llevó a ser partícipe de las fiestas celebradas en el pueblo de San Esteban, en Oaxaca, como representante de la comunidad en Tijuana. De la misma forma colaboró con el proyecto Nido de Lenguas Ñu Viko (sobre la revitalización de la lengua mixteca), que dirigía Claudio Hernández (profesor de primaria) con apoyo del Instituto Nacional de Lenguas Indígenas (INALI) y de la Comisión Nacional para el Desarrollo de los Pueblos Indígenas (CDI). La participación de Sergio, sin ser hablante de mixteco, consistía en llevar y traer a niños y niñas en su coche, traslado que hacía desde sus casas a donde se impartía el taller, su interés al hacerlo era que se involucraran con lo que llama su cultura. La personalidad de Sergio permite ver su emoción al referir su historia, y considerarse como un joven desde su etnicidad, la cual no está sostenida sobre el fundamentalismo de las prácticas y tampoco en el cómo éstas deben realizarse, sino desde una identificación que le permite ser indígena en un entramado de lo urbano.

He seguido algunas trayectorias de quienes han llegado a la ciudad ya siendo jóvenes, principalmente con quienes provienen de Oaxaca. Luego de sortear dificultades relacionadas con la educación, trabajo y racismo, y por otro lado conocer las dinámicas de Tijuana y sus pobladores (indígenas y no), se han envuelto en actividades, y desde una experiencia joven han logrado que niñas, niños y otras y otros jóvenes se inserten también. Las etnicidades desde este punto parten del sistema simbólico, pero no sólo de aquél donde geográficamente se les ubica (la ruralidad) sino, también desde la ciudad, donde las reconfiguraciones simbólicas y de significaciones no tienen una intención de perpetuidad o bien de mantenerlas en una cultural estática que se sostiene en la grupalidad, sino desde las propuestas individuales dinámicas, una acción donde estos sujetos políticos hacen explícita su experiencia urbana y diversifican a las propias juventudes en los espacios de convergencias que en ocasiones son convulsionados por cambios, posibilitando así las redefiniciones, en las que Rita Segato encuentra a los límites de la Nación,

Más acá de aquélla frontera hemisférica, los límites de la Nación hoy territorios donde historias particulares consagraron fisuras $\mathrm{y}$ líneas de clivajes, y articularon entidades sociales diversas por ellas diseñadas... La tensión entre la Nación con voluntad unitaria, por un lado, y la pluralidad fundada por ese encuentro interétnico por el otro, es constitutiva de esas naciones, siendo la estructura de estas relaciones la que proporciona un lenguaje o modelo para incorporar la presencia de otros componentes discriminables en el conjunto de la Nación..." (Segato, 2007: 183). 
De tal forma que no puede rehuirse al hecho de que, en México, como en otros países latinoamericanos, la idea de nación se ancla en lo mestizo y a partir de esto se define al indígena. López, García y Ríos, analizan la retórica nacionalista del mestizo en la historia de México, y refieren cómo esa figura basada en una idea de mezcla, india-europea, fue un intento de incluir la otredad indígena, y sin embargo ha conllevado social, cultural y políticamente a su exclusión, por la "utilidad ideológica como herramienta de homogenización y estabilización social, y quienes también exponen (se refieren a historiadores, antropólogos y críticos culturales) el racismo oculto, las políticas excluyentes y las asimetrías de poder antidemocráticas que esa imagen condona" (O. Gall en López, García y Ríos. 2017: 153). Cuando la etnicidad queda comprendida desde estos términos no se refiere a que los grupos étnicos queden sometidos a los lugares donde son colocados por el Estado, sino de las interacciones que desde ahí se tejen, como lo observamos en el papel activo de los jóvenes.

Lo anterior queda aludido en un entendimiento del caso contextual, donde desde la institucionalización de la juventud no se perciben a los y las jóvenes con adscripción étnica, y son los adultos de los grupos los que intentan ver a dichos jóvenes, pero lo hacen priorizando que en un futuro serán adultos que cuidarán su cultura.

Para continuar con la narrativa desde el yo, entiendo el yo como gobierno de sí mismo por sí mismo en su articulación con las relaciones con los otros (Foucault, 1990), enfoco a Dennis, de 24 años, quien nació en San Miguel el Grande, en Oaxaca, se reconoce mixteca y habla la lengua, misma que aprendió a los nueve años, por interés propio, porque su familia no la hablaba. Creció en San Miguel y por la fuerte red de migración establecida entre Tijuana y su pueblo fue que llegó a la ciudad, con el interés de realizar estudios universitarios que realizó al cursar la licenciatura de Psicología. Al vivir en Tijuana, trabajando y estudiando, Dennis consideraba que algo le hacía falta,

Necesitaba también integrarme a algo más, en ese tiempo que estuve cuidando a mi sobrino iba a Camino Verde (colonia donde hay una concentración de mixtecos de San Miguel) en Camino Verde allá tengo una hermana también y se me hacía muy interesante, me gustaba mucho ir porque llegar a Camino Verde era, como casi volver a San Miguel [...]fue así como conocí la Organización de San Miguel el Grande y cómo se organizaba, que hacían fiestas, que la misma comunidad se organiza para hacer sus reuniones[...] y me gustó mucho la verdad como trabajaban y, también conocí a la Asociación de Suu ni marii que ellos estaban impulsando lo de la fiesta patronal [...] tocando el tema de las danzas $[\ldots]$ me interesó [y] 
quise participar con ellos y me integré como instructora de danza y estuvimos un rato compartiendo en el grupo y, me gustó mucho como fue fluyendo.

Fue así que se relacionó con personas de otros grupos como mazahuas y zapotecos, algunos danzantes con mayor experiencia, los ensayos se realizaban en diferentes lugares que les facilitaban amigos; lograron que se conformara un grupo de danza de la etnia Ñu sávi y continuaron en conjunto con otros grupos de danzantes, motivo por el cual los refiere como un colectivo. Aun considerando que prácticas como ésta son de mucha importancia, al igual que hablar la lengua materna, Dennis expresa que lo conveniente es abrir nuevos panoramas, ser jóvenes con mayor participación política para posicionarse y saberse parte del entorno.

De esto modo la etnicidad constituye lazos que permiten tener una pertenencia étnica distinta a la marcada por la normativa de los adultos. El autoreconocerse y el afirmarse joven indígena precisan de un ejercicio introspectivo que resulta complicado, y pudiera ser una de las razones para que estemos refiriendo a unos pocos jóvenes con esas características, que se nombran indígenas no solo por la herencia familiar. Desde el yo, la etnicidad se vuelve una forma de presencia política que increpa con lo que se relaciona, sobre todo con una tradición de gestión, donde pareciera que estas y estos jóvenes no tiene una aportación para mejorar la vida de los indígenas en la ciudad, y sin embargo continúan en simultaneidad con otros procesos, como veremos enseguida.

\section{Panorama "previsor": actividades y cuidados}

Para ir concluyendo y retomar en qué escenario se conforman las etnicidades, referiré brevemente a las actividades políticas de los indígenas en Tijuana, estas en relación con el Estado ${ }^{8}$. Aludí ya a las actividades que durante años han realizado las asociaciones con líderes y

${ }^{8}$ En el estado de Baja California, de los cinco municipios que lo componen son cuatro los que tienen funcionarios indígenas, en Tecate Norma Meza Calles, kumiai (etnia nativa), es jefa de comunidades indígenas dentro de la administración municipal (2016-2019). Cristina Solano Díaz (mixteca del estado de Guerrero) es directora de Desarrollo Social en Ensenada (20162019), Jesús Romero (purépecha del estado de Michoacán), es Director del Departamento para el Desarrollo de los Pueblos Indígenas, en el municipio de Playas de Rosarito (2016-2019). Mónica González, fue recientemente nombrada delegada del Instituto Nacional de los Pueblos Indígenas en Baja California (2019-2025), ella es indígena nativa cucapá. Maribel Velasco (mixteca de Oaxaca) es encargada de la Coordinación de Asuntos Indígenas en Tijuana, en la administración municipal que concluye en diciembre de 2019. Dennis Aparicio fue la encargada del Módulo de Atención a Comunidades Indígenas, durante los meses que este se mantuvo en el gobierno municipal de Jorge Astiazarán (presidente municipal de Tijuana de 2013 a 2016). 
lideresas, una que ha impactado en la administración municipal actual (20162019) es haber logrado que se aprobara el reglamento de Pueblos Indígenas, donde se reconocen como sujetos de derechos, lo que consecuentemente permitirá tener un espacio permanente en las administraciones municipales a través de la Coordinación de Asuntos Indígenas en Tijuana, que hasta el momento preside la abogada mixteca Maribel Velasco, quien cuenta con una amplia experiencia, ha sido presidenta de asociación, es ex directora de la Casa de la Mujer Indígena Donají y actualmente es consejera electoral.

Con ciertos aspectos administrativos aún por resolver, la Coordinación de Asuntos Indígenas depende de Desarrollo Social y aún no ha concretado sus funciones. Maribel inició sus actividades sin un espacio fijo para laborar, tiene una agenda de trabajo donde comenta prioriza el enfoque intercultural "porque si bien dicen que ustedes (funcionarios) atienden igual a todo mundo tenemos nuestras especificidades (las y los indígenas) como comunidad y a pesar de [tener] varios años [en] Tijuana no nos quitamos esa cosmovisión que tenemos en nuestra comunidad desde donde venimos".

Aun teniendo que depender de la agenda de los gobiernos municipales (el actual y los que vendrán), es un logro importante el haber concretado la conformación tanto del Reglamento como de la Coordinación de Asuntos Indígenas, pues se trata de una instancia permanente solicitada con anterioridad a varias administraciones, representa además una estabilidad de donde partir para las propuestas de las organizaciones, debido a que anteriormente con cada cambio de presidente municipal el trabajo en lo administrativo y la gestión parecían partir de cero; cabe añadir que estas formas de gestar lo étnico, no niega a las otras, sino que comparten el proceso con resultados heterogéneos.

El caso de Edgar, nacido en Tijuana, también auto reconocido con adscripción étnica además de definirse como tijuanense, es relevante porque sus participaciones y propuestas las ha realizado desde la actividad política de los procesos electorales. Estuvo en el equipo de Gastón Luken, quien en 2016 obtuvo su registro para ser candidato independiente y postularse a la alcaldía de Tijuana. Edgar se ha mantenido crítico a la forma de hacer política local hacia la población indígena, y de cómo se realiza desde las propias agrupaciones. En 2018, en miras de la elección para Presidente de la República Mexicana declaró, "a mí lo que me interesa es cambiar esa idea de victimización para 
nuestra gente, somos fuertes, siempre lo hemos sido, esta es nuestra historia" (El Universal, 2018).

Con esos intereses y con la convicción de que el cambio puede provenir desde el mismo sistema si en este hay representantes indígenas con perspectivas distintas a un asistencialismo, Edgar ha realizado una propuesta para el proceso electoral 2019 (en Baja California habrá elecciones para las alcaldías y la gubernatura del estado) para lo cual presentó una demanda ante el Instituto Estatal Electoral de Baja California, donde solicitó una postulación de candidaturas indígenas en los distritos donde haya mayor cantidad de población indígena ${ }^{9}$. Lo anterior ha resultado ser un precedente en la región, por intentar establecer candidaturas obligatorias de representación, señalando la importancia de que se tengan lazos comunitarios.

Las posturas de Edgar quedan claras, critica a los mecanismos homogeneizados del hacer étnico y queda al margen de las genealogías organizativas,

\footnotetext{
${ }^{9}$ Entre las propuestas de la solicitud se encuentra, que, por el principio de mayoría relativa, en el distrito electoral local en el que haya mayor cantidad de población indígena, los partidos políticos deberán postular a una persona indígena que cuente con un vínculo comunitario. (Telio Suárez, Facebook, 7 de diciembre, 2018, https://www.facebook.com/profile.php?id=10000 7734587239).
}

razón por la cual algunas veces no encuentra una legitimación desde quienes son dirigentes de agrupaciones; su condición juvenil lo ha llevado a compartir con otros indígenas con quienes tiene ciertas inquietudes sobre las etnicidades como Sergio y Dennis, pero se coloca en prácticas distantes.

Hasta aquí me ha parecido importante abordar las condiciones de este escenario cambiante, en donde hay jóvenes que articulan su individualismo, que no se aprueba entre los adultos, en todo caso no se trata de particularizar la etnicidad, sino de plantearla como plural,en un entrecruzamiento con la historia colonial, las migraciones, las espacialidades, de esta forma las configuraciones de una dinámica publica de lo étnico se relaboran. Considero importante de la misma manera acentuar que luego de las experiencias con segundas generaciones, donde hubo un distanciamiento propiciado por las familias para que niños y niñas no aprendieran alguna de las lenguas maternas, por saberse como marcador de exclusión, hoy nos encontramos con un interés creciente por involucrarlos, prefigurando posiblemente su juventud, lo cual se hace desde el cuidado del conjunto, de tal manera que en los siguientes párrafos expondré de manera breve algunas de las formas de esta dinámica. 
Niños y niñas que serán jóvenes

Los y las niñas con adscripción étnica en Tijuana, pueden ser inscritas en el Jardín de niños, Primarias y Secundarias del sistema escolar intercultural bilingüe que operan en la ciudad. Estos centros escolares se localizan en las zonas donde hay mayor densidad de población indígena. Como parte del planeamiento del sistema se prevé la enseñanza de las lenguas, así como otros ejes culturales, sin embargo, en la práctica esto no se cumple a cabalidad, a pesar de encontrarnos con algunas primarias que intentan realizarlo al hacer actividades como el festejo de día de muertos, es el caso de la primaria Vée Saa Kua'a, ubicada en Valle Verde, una colonia con concentración de mixtecos de Guerrero y mixtecos nacidos en Tijuana.

Sin que el medio institucionalizado de la educación tenga un impacto visible en las definiciones étnicas de los niños y niñas (Sergio por ejemplo asistió a una escuela de este sistema $y$ dice no considerar que ahí fue educado desde lo cultural), otro recurso al igual que como se ha hecho con los y las jóvenes, es que participen en las danzas. Son enseñados por adultos u otros jóvenes, como en el caso de Rogelio, danzante que tiene un grupo y comenta que al verlo danzar niños y niñas se acercan a preguntarle. También dice encontrar una limitante, pues ante el cambio religioso en la frontera, quienes ya no son católicos, sino evangélicos $\mathrm{o}$ pentecostales no permiten a sus hijos e hijas esta práctica, debido a que sus presentaciones con mayor regularidad se realizan en festejos religiosos católicos. En las siguientes fotografías podemos observar la participación de los danzantes menores. En la primera lo realizan como parte de la algarabía del festejo patronal mixteco a la Virgen de las Nieves. En la segunda se muestra a un niño con máscara en otro de los festejos, la danza de la que es parte se llama de Los rubios, para la cual ensayan en Tijuana, pero se presenta en distintas ciudades a donde son invitados, en este caso se trata de Mexicali, capital del estado, donde el grupo zapoteca celebraba a San Judas Tadeo. 
IMAGEN 2 Niños danzantes, Cañón del Pato, festejo de la colonia Obrera a la Virgen de las Nieves, mixteca de Oaxaca, Tijuana, 2016. Olga Lorenia Urbalejo.

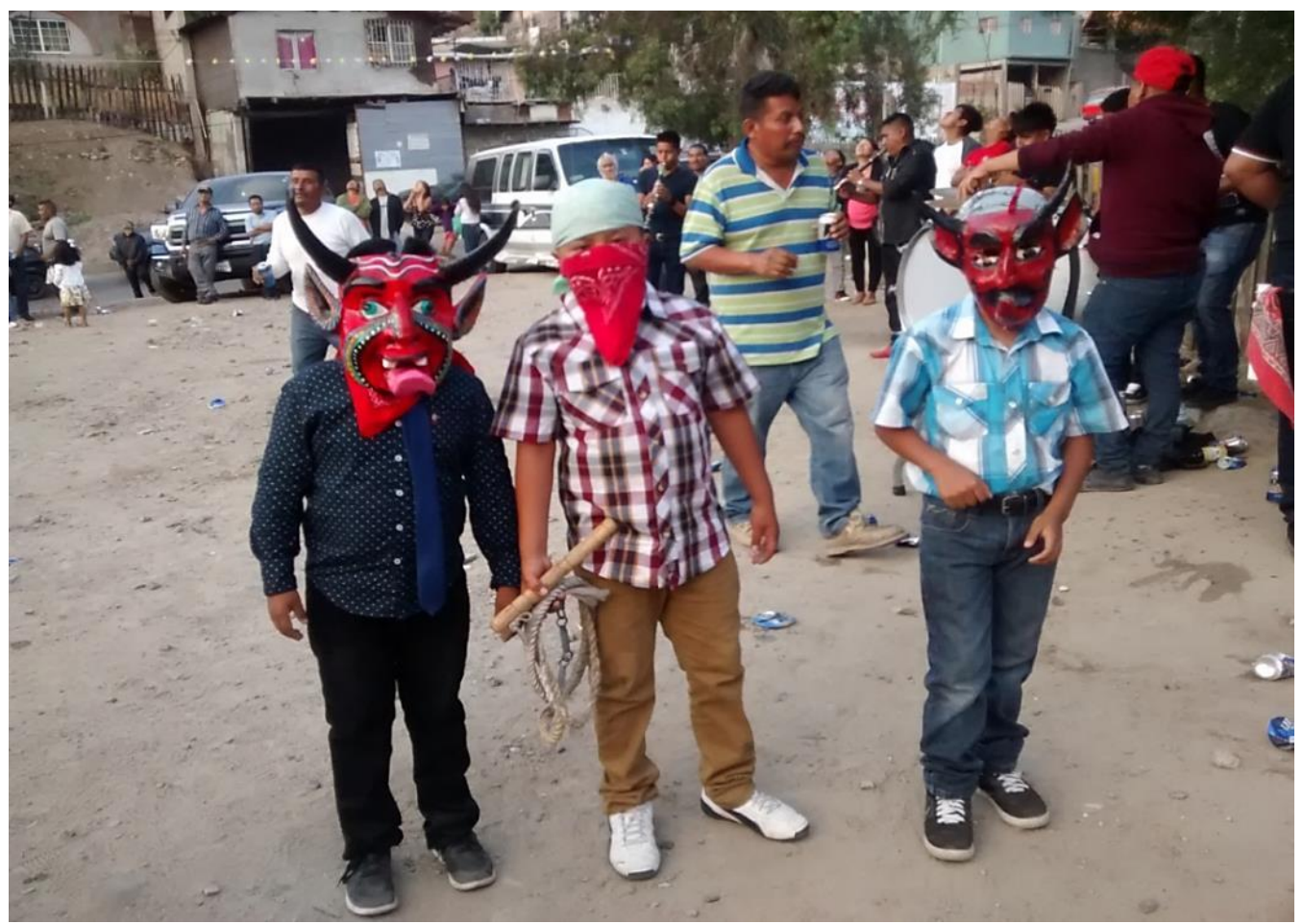

IMAGEN 3 Danzante de los rubios, Mexicali, 2018. Olga Lorenia Urbalejo.

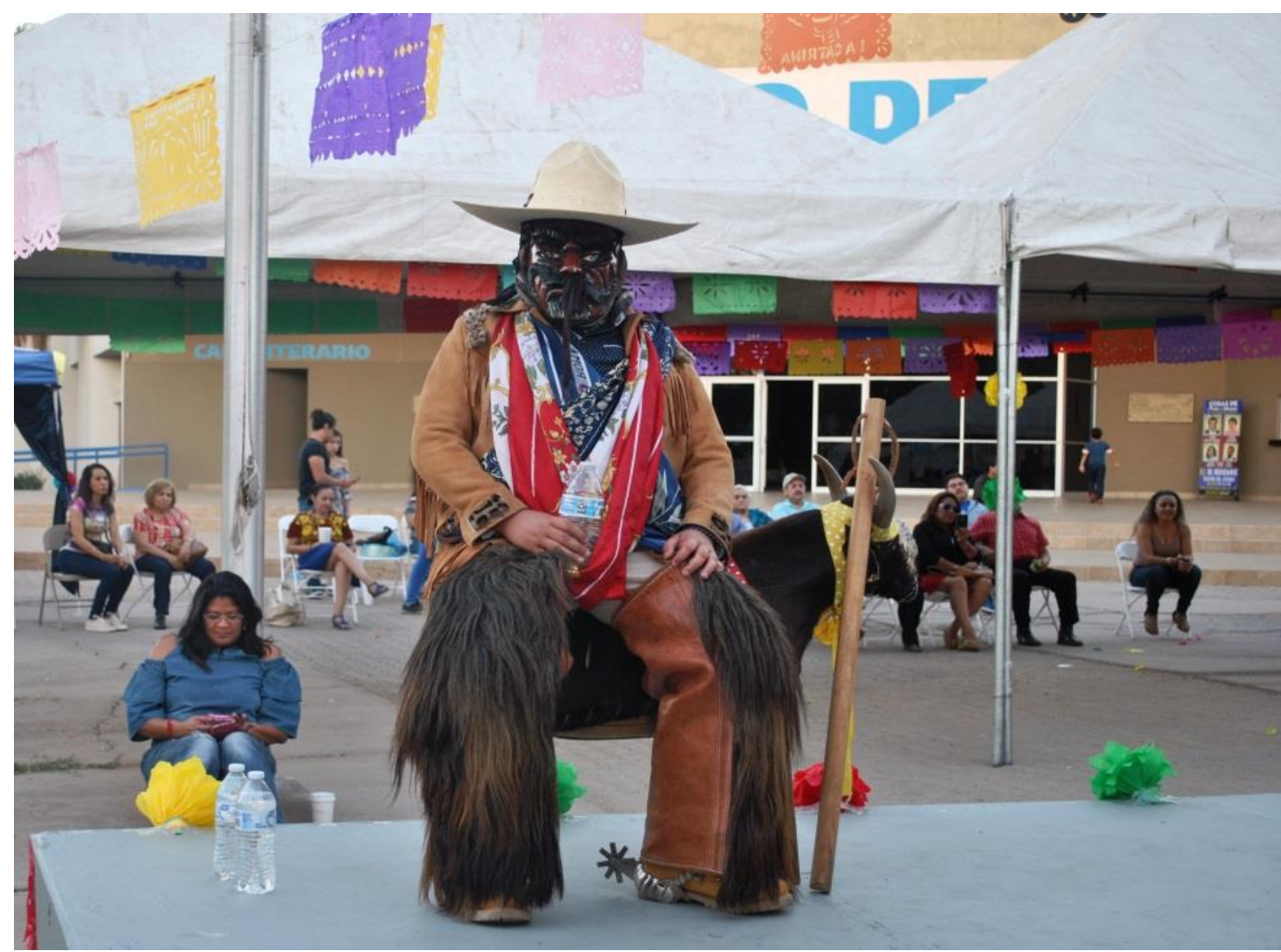


De esta forma, talleres para hablar la lengua, música y danza continúan como articuladores culturales que, como hemos visto, pueden ser el medio para la identificación. Otro proyecto es el que se realiza en coordinación con el Instituto Estatal de la Mujer y la Casa de la Mujer Indígena Donají, en el que también colabora Maribel Velasco. Como ya comenté, ha sido preocupación de los y las legisladoras detener el trabajo que realizan niños y niñas que acompañan a sus madres a vender o pedir limosna en las calles; los días que ahora ocupan para la actividad son los fines de semana, pero se hace durante el día y noche, por lo que se ve como un tema de derechos humanos. Maribel ha comentado a las funcionarias que intentan concientizar a las madres, que no se trata sólo de ofrecerles alternativas de autoempleo (algunas de estas impuestas, como la elaboración de artesanía), y tampoco de proceder bajo amenazas de quitarle a sus hijos e hijas. El proyecto se trabajará por módulos, a realizarse en dos zonas escolares (de educación intercultural) e integrará a los y las docentes puesto que conviven con quienes trabajan en las calles. Se espera el proyecto se inicié en 2019, una vez que se hayan conseguido fondos.
Maribel se mantiene interesada en concientizar a los niños y niñas de lo que llama su identidad. Participando en otros talleres comenta que los hace observar que lo étnico está su cotidianidad, esto ante la negativa de verse como indígenas, así refiere el diálogo que entabla:

\begin{abstract}
hay que revisar que comimos y es en la comida en la que menos perdemos nuestra identidad, ¿qué hace mamá en casa? Tal vez adoptamos el Halloween, el de acción de gracias, pero siempre va a haber tamales oaxaqueños de hoja de plátano, siempre va a haber un mole [...] depende del contexto de tu comunidad, siempre va a existir y a veces que dices es una receta de la abuela de la abuela, pero eso es desde nuestra identidad. Entonces dicen ¡ah! no lo pensé. Entonces ese es de los trabajos o de los retos más grandes que se tienen con estas segundas generaciones.
\end{abstract}

\section{Consideraciones finales}

En este artículo se han planteado las complejidades de los y las jóvenes con adscripción étnica que viven en Tijuana y que deciden hacer frente a un panorama y dinámicas que los dejan fuera de los campos de juventud y etnicidad, esta última comprendida desde la óptica adultocentrista. Los posicionamientos discursivos provenientes de habitantes de 
Tijuana y que resultan racistas, así como la no inclusión de la institución que podríamos suponer tendría la facultad para hacer un ejercicio de vinculación interseccional juventud-etnia, y en cambio continua con una invisibilidad en miras de fortalecer otros aspectos de lo juvenil, conforman una de las partes del engranaje donde se diversifica las etnicidades de los y las jóvenes. La importancia de mostrar el escenario amplio y complejo con el cual tienen relación, es debido a que ante estos mismos atenuantes hay una generalidad de jóvenes que se desvinculan de lo que los identifica con lo étnico y construyen una juventud con características que consideran más urbanas, aun reconociendo que por los lazos familiares tienen una continuidad con sus grupos indígenas.

Por otro lado, vimos que la llamada problemática indígena en la ciudad ha sido expuesta y resuelta a través de los líderes y lideresas, lo cual marca antecedes de cómo deben ser vistos los indígenas y cuáles son sus intereses. En una tradición cultural también se prevé que se priorice a la grupalidad, pero cuando la experiencia de vida ha cambiado, y repercute en cómo resulta la etnicidad, se observan sus formas distintas de ser y practicarla, aun en conjunción con el Estado, desde donde se gestionan además las políticas de la igualdad y la diferencia, como se puede ver al haber aportado a ese panorama que llamé previsor, en el cual hay acciones desde una política más convencional y por otro lado continua un cuidado de la comunidad.

En lo particular sería pertinente dar un seguimiento a las demandas presentadas ante el Instituto Estatal Electoral de Baja California, así como al funcionamiento de la Coordinación de Asuntos Indígenas. En dicho seguimiento sería importante ver si otras ciudades logran un puesto permanente dentro de las administraciones, debido a que en los demás municipios está a criterio de asuntos de presupuesto.

Con los casos expuestos vimos que, aun tratándose de experiencias distintas respecto a la migración, en la ciudad se ha permitido conformar una etnicidad identificada desde el yo, ésta con un primer acercamiento que parece el común entre la dinámica étnica de Tijuana, practicar danzas en el caso de Sergio y Dennis, pero con la determinación de dirigirse a otras áreas. La propuesta para continuar con el análisis del tema sería, cómo abordar a estos nuevos sujetos políticos y en largo plazo y observar cómo influyen en las reconfiguraciones y cómo se insertan a esos procesos inacabados. 


\section{Referencias bibliográficas}

BELTRÁN, Carlos López, et al. Genómica mestiza: Raza, nación y ciencia en Latinoamérica. Fondo de Cultura Económica, 2017.

BALARDINI, Sergio. "De los jóvenes, la juventud y las políticas de juventud". En Última década, Vol. 8, no 13, pp. 11-24, 2000.

CAMPOS-DELGADO, Amalia, Alberto Hernández. "Vivir en la frontera: una mirada a las prácticas socioculturales en la región Tijuana-San Diego." En Alberto Hernández y Amalia Campos-Delgado (coords.), Líneas, límites y colindancias: mirada a las fronteras desde América Latina, México, Colef/CIESAS, pp. 143176, 2015.

LÓPEZ BELTRÁN, Carlos, Vivette García, Mariana Ríos. "El mestizo en disputa: la posibilidad de una genómica nacional en México". En López Beltrán Carlos, Peter Wade, Eduardo Restrepo, Ricardo Ventura (eds.) Genómica mestiza: Raza, nación y ciencia en Latinoamérica, Fondo de Cultura Económica, México, pp. 146-182, 2017.

LÓPEZ, Jahel. "Las mujeres indígenas jóvenes en el espacio público de la ciudad, una experiencia aún por conocer". En Meyibó, No.16, pp.19-43, 2018.

FOUCAULT, Michell. Tecnologías del yo. Paidós/ICE-UAB, Barcelona, 1990.

KROPFF, Laura y Valentina Stella. "Abordajes teóricos sobre las juventudes indígenas en Latinoamérica" en LiminaR vol.15 no.1, San Cristóbal de las Casas, ene-jun 2017.
MARTÍNEZ, Gabriela, "Los indígenas somos fuertes, lo hemos sido, está en la historia": Édgar Montiel, El Universal, 2018.

OSSOLA, María Macarena. "Etnografía con jóvenes en el espacio urbano Entrevista con Maritza Urteaga." En Cuadernos de antropología social, No.39, 2014, pp. 151-169.

SANTOS, Milton. "Espacio y método", en Gestión y Ambiente, vol. 12, no 1, 2009.

SEGATO, Rita Laura. La nación y sus otros: raza, etnicidad y diversidad religiosa en tiempos de políticas de la identidad. Prometeo Libros Editorial, 2007.

PIÑERA, David, Jesús Ortiz y Alejandro Lugo. "Primeros pobladores y época misional". En Historia de Tijuana. Semblanza general, David Piñera y Jesús Ortiz, UABC, pp 19-42, 1985.

URBALEJO CASTORENA, O. Lorenia, La ciudad como espacio vivido: mixtecos de Guerrero en Tijuana. Editorial Académica Española, Saarbrücken, Alemania, 2011.

URBALEJO CASTORENA, O. Lorenia. Imaginarios juveniles. Un análisis desde la condición étnica y urbana de los jóvenes mixtecos en Tijuana, tesis de doctorado, Universidad Autónoma MetropolitanaIztapalapa, Ciudad de México, 2014.

VELASCO ORTIZ, Laura (coord.). Condiciones de vida e integración social de la población indígena en el municipio de Tijuana, Baja California. Cuadernos de investigación, CDI, Tijuana, 2008.

VELOZ CONTRERAS, Areli. "Las contiendas por la ciudad: criminalización, muertes y organización política en torno a la diversidad sexual en Tijuana". Culturales, vol. 5, no 1, p. 85120, 2017. 
URTEAGA DEL POZO, Maritza. Lo juvenil en lo étnico. Migración juvenil indígena en la sociedad contemporánea mexicana. En Ponto e Vírgula, vol. 4, pp.261-275, 2008.

URTEAGA DEL POZO, Maritza. Género, clase y etnia. Los modos de ser jóvenes". En Reguillo, Rossana. Los jóvenes en México. Fondo de Cultura Económica, 2017.

https://www.copladebc.gob.mx/ Comité de Planeación para el Desarrollo del Estado (COPLADE)

https://www.eluniversal.com.mx/estados/los -indigenas-somos-fuertes-lo-hemos-sidoesta-en-la-historia-edgar-montiel(El Universal, 2018).

http://www.imjuv.tijuana.gob.mx/

https://www.facebook.com/profile.php?id= 100007734587239 